\title{
Access to Medical Services in Korean People With Spinal Cord Injury
}

\author{
Jeong-Gil Kim, MD, Hyung Seok Nam, MD, Byungkwan Hwang, MD, Hyung-Ik Shin, MD
}

Department of Rehabilitation Medicine, Seoul National University Bundang Hospital, Seongnam, Korea

Objective To investigate the accessibility of medical services for Korean people with spinal cord injury (SCI) compared to the control group (CG) and to evaluate significantly related factors.

Methods A total of 363 community dwelling people with chronic SCI were enrolled and 1,089 age- and sexmatched subjects were randomly selected from the general population as the CG. Self-reported access to medical services was measured by asking "Have you experienced the need for a hospital visit in the last year but could not?". This was followed up by asking the reasons for not receiving services when medically necessary. Variables, including lack of finances, difficulties making medical appointments, and lack of transportation were evaluated for accessibility to medical services.

Results Sixty subjects (16.5\%) in the SCI group had difficulties receiving medical services due to a lack of accessibility, compared to $45(4.1 \%)$ in the CG $(\mathrm{p}<0.001)$. Variables causing difficulties receiving medical services were lack of transportation ( 27 persons, $45 \%$ ), lack of finances ( 24 persons, $40 \%$ ), and difficulty scheduling hospital appointments (9 persons, 15\%) in the SCI group. In the CG, availability (lack of available time) and acceptability (deciding not to visit the hospital due to mild symptoms) were the reasons for not receiving medical care.

Conclusion People with SCI experienced limited accessibility to medical services, which was due to environmental rather than personal factors compared to that in the CG. Therefore, development of social policies to reduce or remove environmental variables is necessary.

Keywords Health services accessibility, Spinal cord injuries, Healthcare disparities

Received August 28, 2013; Accepted November 26, 2013

Corresponding author: Hyung-Ik Shin

Department of Rehabilitation Medicine, Seoul National University Bundang Hospital, 82 Gumi-ro 173beon-gil, Bundang-gu, Seongnam 463-707, Korea

Tel: +82-31-787-7733, Fax: +82-31-787-4056, E-mail: hyungik1@snu.ac.kr

(c) This is an open-access article distributed under the terms of the Creative Commons Attribution Non-Commercial License (http://creativecommons. org/licenses/by-nc/3.0) which permits unrestricted noncommercial use, distribution, and reproduction in any medium, provided the original work is properly cited.

Copyright $\odot 2014$ by Korean Academy of Rehabilitation Medicine

\section{INTRODUCTION}

Spinal cord injury (SCI) can lead to secondary functional losses, early onset chronic diseases, and complications, such as urinary tract infection, osteoporosis and pressure sores [1]. Although these conditions require medical treatment, people with SCI might face barriers to access medical services. For example, motor impairment in people with SCI makes hospital visits difficult if there is inaccessible transportation. In addition, people with SCI are less economically active than that of the general population (GP) in Korea, and income level can influence 
the use of medical services $[2,3]$.

Chen and Hou [4] categorized the unmet healthcare needs into three characteristics of accessibility, availability, and acceptability. Inaccessible transportation, poor economic status and difficulty scheduling hospital appointments affect accessibility. Not receiving medical services when they are required or being discouraged due to long waiting times characterizes availability. Acceptability is related to the personal environment and includes mild symptoms and other reasons, such as fear of doctors or believing that care is not necessary.

Recently, Hwang et al. [5] reported that unmet needs for medical services in Korean people with disabilities are much higher than that of the GP. Their study revealed that the unmet needs for medical services of disabled people were due to accessibility of medical services and, specifically, the economic burden and inaccessible transportation. In contrast, GP was associated with availability, such as a lack of time.

These kinds of unmet needs for medical services could be different according to the characteristics of the disability [6-11]. For example, accessibility to medical services for people with SCI can be different from those with mental health or internal organ disorders because people with SCI have a problem with physical activity rather than a cognitive disorder or medical instability [12].

In this study, we investigated the accessibility of medical services for a Korean population with SCI compared to a control group (CG) and evaluated the influential factors.

\section{MATERIALS AND METHODS}

\section{Subjects}

We compiled data from two surveys conducted by the 2010 Survey on Health and Nutrition of People with SCI from the Korea Spinal Cord Injury Association (KSCIA) and the Korean Ministry of Health and Welfare: the 2008 Korean National Health and Nutrition Examination Survey (KNHNES IV). KSCIA (www.kscia.org) is a non-profit, non-governmental organization based on the Internet and led by people with SCI. They have conducted home visiting survey for the health and nutrition. All subjects were members of the KSCIA and volunteered to participate in the survey. Inclusion criteria included existing SCI for people aged $\geq 20$ years for more than 1 year. A to- tal of 374 people with SCI initially participated. However, 363 subjects were finally included because 11 respondents had incomplete data to perform CG matching. We included data from 9,774 normal subjects in the KNHNES survey in 2008 for the CG. KNHNES is a survey conducted by the Korean government every year on 20 randomly selected households in each of the 192 areas nationwide, focusing on national health promotion, by surveying health status, health behaviors, and nutritional status. A total of 1,089 of 9,774 subjects from the GP whose age and gender matched randomly (1:3) were included. We certify that all applicable institutional and governmental regulations concerning the ethical use of human volunteers were followed during the course of this research. This study was approved by the Institutional Review Board of Seoul National University Bundang Hospital (B1109/135-010).

\section{Access to medical services}

Both surveys evaluated unmet needs for medical services by asking the following question: "Have you experienced the need to visit the hospital in the last year but could not?". Those who reported "yes" were considered to have a problem with access to medical services. Reasons for their difficulties accessing medical services were queried with seven possible choices: (1) lack of money; (2) difficulty making hospital appointments; (3) inaccessible transportation; (4) not available when required; (5) discouraged by long waiting time; (6) mild symptoms; and (7) other reasons (e.g., fear of doctors or doubts about treatment efficacy). The respondents were allowed to choose only one reason.

Accessibility consisted of economic status, available transportation, and capability of accessing the appointment system. Respondents who gave reasons (1), (2), or (3) were categorized as having problems with medical service accessibility. Availability is related to difficulties using medical services. Respondents who gave reasons (4) and (5) were categorized as having problems with medical service availability. Acceptability includes personal circumstances and attitudes, such as fear of doctors or believing that care was unnecessary. Reasons (6) and (7) were classified as acceptability problems. In this study, we focused on accessibility (lack of money, difficulty scheduling hospital appointments, and inaccessible transportation) to understand the environmental and 
structural barriers to medical services experienced by persons with SCI experience.

\section{Socio-demographic variables}

Survey items including demographic data and sociopsychological and economic status were selected from the KNHNES. We compared socio-demographic factors between the two surveys and analyzed factors related to disabilities in the survey of people with SCI. Sex, age, and number of family members were investigated for the demographic data. Age groups were classified as $20-39$, $40-59$, and $\geq 60$ years. Number of family members was divided into three groups of living alone, 2-3 members, and $\geq 4$. Marital status, education level, self-perceived health state, experience of visiting an outpatient clinic within the last 2 weeks, and admission to the hospital within the last 12 months were the socio-psychological variables. Marital status was classified as married, single, and no spouse (divorced, widowed, or separated) and evaluated for pre/post injury state. Education level was classified into three categories of elementary school or lower, middle to high school, and college or higher. Each participant was asked the question "What do you think about your health status?" to evaluate self-perceived health. The reports of all participants were divided into five categories of very good, good, moderate, poor, and very poor. In addition, the experience of visiting an outpatient clinic within the last 2 weeks and admission to a hospital within the last 12 months was evaluated by yes or no. Economic variables consisted of income and occupation. Income was divided into four quartiles (Q) [5]. We used monthly householdequalized income. The cutoff value of Q1 was 49.5, that of Q2 was 106.07, and that of Q3 was 176.78 (million Korean won).

Monthly household-equalized income $=$

$$
\text { household income } / \sqrt{\text { (the number of family members) }}
$$

Occupation was divided into white collar jobs, blue collar jobs, and no occupation (housewife, student, or unemployed). Additionally, data related to SCI were added such as disability rating and type of paralysis. Disability rating was divided into first class and second class or below. Type of paralysis was categorized into tetraplegia and paraplegia.

\section{Statistical analysis}

The statistical analysis was performed using SPSS ver. 19.0 (SPSS Inc., Chicago, IL, USA). The chi-square test was used to compare socio-demographic characteristics and to access medical services between the SCI group and the CG. In addition, a multiple logistic analysis for the entire dataset (SCI and CG together) was performed to investigate significant factors related to accessibility to medical services in the SCI group.

\section{RESULTS}

\section{Sample characteristics}

As shown in Table 1, this study included 363 subjects in the SCI group and 1,089 subjects in the CG. The SCI and CG groups were 1:3 age and gender matched. Mean age was 59.2 years (standard deviation, 17.02), the proportion of males was $83.2 \%$, and that of females was $16.8 \%$. The age group of 40-59 years was the most frequent (63.4\%), the 20 -39 year group comprised $29.8 \%$, and $\geq 60$ years was $6.9 \%$. The proportion of people living alone was $18.4 \%$ in the SCI group compared to $4.4 \%$ in the CG. The most frequent number of family members in the SCI group was $2-3$ (44.7\%), but in the CG, $54.4 \%$ of the subjects had $\geq 4$ family members $(\mathrm{p}<0.001)$. The proportion of subjects who were married was $76.6 \%$ in the CG, whereas $47.7 \%$ of SCI group was married, $47.4 \%$ were unmarried, and $5.0 \%$ had no spouse during the pre-injury period but the no spouse portion increased to $13.7 \%$ after injury $(p<0.001)$. The majority of the subjects in the CG had college or higher education level (71.4\%), whereas $61.2 \%$ of the subjects in the SCI group completed middle to high school $(p<0.001)$. The proportion of participants who reported a "good" self-perceived health state was highest in the CG (39.9\%), whereas the proportion of participants who reported "moderate" was the highest in people with SCI $(46.6 \%)$ ( $p<0.001)$. In the SCI group, $46.8 \%$ of the subjects had visited the outpatient clinic within the last 2 weeks, but it was only $26.2 \%$ in the CG ( $\mathrm{p}<0.001)$. A total of $31.5 \%$ of people with SCI had been admitted to the hospital within the last 12 months, whereas it was $8.4 \%$ in the CG $(\mathrm{p}<0.001)$.

A significant difference was observed between the CG and the SCI group after the injury for the proportion of occupational groups. Blue collar and no occupation was $5.3 \%$ and $73.7 \%$ in the SCI group, respectively, whereas 
Table 1. Socio-demographic characteristics of the study subjects

\begin{tabular}{|c|c|c|c|}
\hline Characteristic & $\begin{array}{c}\text { SCI group } \\
(n=363)\end{array}$ & $\begin{array}{c}\text { Control group } \\
(n=1,089)\end{array}$ & p-value* \\
\hline Age (yr) & & & 1.000 \\
\hline 20-39 & $108(29.8)$ & $324(29.8)$ & \\
\hline $40-59$ & $230(63.4)$ & $690(63.4)$ & \\
\hline$\geq 60$ & $25(6.9)$ & $75(6.9)$ & \\
\hline Gender & & & 1.000 \\
\hline Male & $302(83.2)$ & $906(83.2)$ & \\
\hline Female & $61(16.8)$ & $183(16.8)$ & \\
\hline Number of family & & & $<0.001$ \\
\hline 1 & $66(18.4)$ & $48(4.4)$ & \\
\hline $2-3$ & $160(44.7)$ & $449(41.2)$ & \\
\hline$\geq 4$ & $132(36.9)$ & $592(54.4)$ & \\
\hline \multirow[t]{2}{*}{ Marital status (pre- vs. post-injury) } & & & Pre $<0.001$ \\
\hline & & & Post $<0.001$ \\
\hline \multirow[t]{2}{*}{ Married } & Pre $173(47.7)$ & $833(76.6)$ & \\
\hline & Post $198(54.5)$ & & \\
\hline \multirow[t]{2}{*}{ Unmarried } & Pre $172(47.4)$ & $182(16.7)$ & \\
\hline & Post $115(31.7)$ & & \\
\hline \multirow[t]{2}{*}{ Divorced, widowed, separated } & Pre $18(5.0)$ & $73(6.7)$ & \\
\hline & Post 50 (13.7) & & \\
\hline Income & & & $<0.001$ \\
\hline 1st quartile & $13(4.8)$ & $130(12.3)$ & \\
\hline 2nd quartile & $102(35.2)$ & $228(21.5)$ & \\
\hline 3rd quartile & $50(17.2)$ & $334(31.5)$ & \\
\hline 4th quartile & $125(43.1)$ & $367(34.7)$ & \\
\hline Education & & & $<0.001$ \\
\hline$<$ Elementary school & $25(6.9)$ & $159(14.6)$ & \\
\hline$<$ High school & $222(61.2)$ & $152(14.0)$ & \\
\hline College \& over & $116(32.0)$ & $778(71.4)$ & \\
\hline Occupation & & & $<0.001$ \\
\hline White collar & $76(21.1)$ & $224(20.6)$ & \\
\hline Blue collar & $19(5.3)$ & $606(55.6)$ & \\
\hline No occupation & $266(73.7)$ & $259(23.8)$ & \\
\hline Self-perceived health & & & $<0.001$ \\
\hline Very good & $16(4.4)$ & $70(6.4)$ & \\
\hline Good & $78(21.5)$ & $434(39.9)$ & \\
\hline Moderate & $169(46.6)$ & $411(37.7)$ & \\
\hline Poor & $85(23.4)$ & $151(13.9)$ & \\
\hline Very poor & $15(4.1)$ & $23(2.1)$ & \\
\hline Outpatient clinic visit within the last 2 weeks & & & $<0.001$ \\
\hline Yes & $170(46.8)$ & $285(26.2)$ & \\
\hline No & $193(53.2)$ & $804(73.8)$ & \\
\hline Hospital admission within the last 12 months & & & $<0.001$ \\
\hline Yes & $113(31.5)$ & $92(8.4)$ & \\
\hline No & $246(68.5)$ & $997(91.6)$ & \\
\hline
\end{tabular}


Table 1. Continued

\begin{tabular}{|c|c|c|c|}
\hline Characteristic & $\begin{array}{c}\text { SCI group } \\
(n=363)\end{array}$ & $\begin{array}{c}\text { Control group } \\
(n=1,089)\end{array}$ & p-value ${ }^{*}$ \\
\hline Disability rating & & & - \\
\hline 1st class & $331(91.2)$ & - & \\
\hline Below 2nd class & $32(8.8)$ & - & \\
\hline Type of paralysis & & & - \\
\hline Tetraplegia & $142(39.8)$ & - & \\
\hline Paraplegia & $215(60.2)$ & - & \\
\hline
\end{tabular}

Values are presented as number of cases (\%).

SCI, spinal cord injury.

*Pearson chi-square test.

Table 2. Percent distribution of reasons for not receiving medical services when needed

\begin{tabular}{|lccr}
\hline & SCI group & Control group & p-value* \\
\hline Unmet needs for medical services & $90(24.8)$ & $205(18.8)$ & 0.016 \\
\hline Accessibility & $60(16.5)$ & $45(4.1)$ & $<0.001$ \\
\hline Availability & $15(4.1)$ & $94(8.6)$ & 0.004 \\
\hline Acceptability & $15(4.1)$ & $66(6.1)$ & 0.190 \\
\hline & & & \\
\hline Accessibility & $60(66.7)$ & $45(22.0)$ & \\
\hline Lack of money & $24(26.7)$ & $40(19.5)$ \\
\hline Difficulty scheduling hospital appointments & $9(10.0)$ & $2(1.0)$ \\
\hline Inaccessible transportation & $27(30.0)$ & $3(1.5)$ \\
\hline Availability & $15(16.7)$ & $94(45.9)$ \\
\hline Not available when required & $7(7.8)$ & $90(43.9)$ \\
\hline Discouraged due to long wait times & $8(8.9)$ & $4(2.0)$ \\
\hline Acceptability & $15(16.7)$ & $66(32.2)$ \\
\hline Mild symptoms & $10(11.1)$ & $52(25.4)$ \\
\hline Other reasons & $5(5.6)$ & $14(6.8)$ \\
\hline
\end{tabular}

Values are presented as number of cases (\%).

SCI, spinal cord injury.

*Pearson chi-square test.

the CG group was $55.6 \%$ and $23.8 \%$ for blue collar and no occupation, respectively $(\mathrm{p}<0.001)$. The disability rating of the subjects in the SCI group was first class in $91.2 \%$ and $8.8 \%$ were second class or below. The type of paralysis was tetraplegia in $39.8 \%$ and paraplegia in $60.2 \%$ of the SCI subjects.

\section{Accessibility to medical services}

Ninety persons with SCI (24.8\%) reported difficulties receiving medical services, which was higher than that in the CG ( $\mathrm{p}=0.016)$ (Table 2). Of the 90 persons with SCI,
$60(16.5 \%)$ answered that they had difficulty using medical services due to accessibility, whereas only 45 (4.1\%) of the 1,089 persons reported access problems in the CG $(p<0.001)$. The most frequently reported reason for inaccessibility to medical services in the SCI group was inaccessible transportation ( 27 persons, $30.0 \%$ ), followed by lack of money ( 24 persons, $26.7 \%$ ), and difficulty scheduling hospital appointments (9 persons, 10.0\%). Lack of available time was the most frequently reported reason (90 persons, $43.9 \%$ ) in the CG, followed by mild symptoms (52 persons, $25.4 \%$ ). 
Table 3. Chi-square tests for inaccessibility to medical services

\begin{tabular}{|c|c|c|c|c|}
\hline & \multicolumn{2}{|c|}{ SCI group } & \multicolumn{2}{|c|}{ Control group } \\
\hline & No. (\%) & p-value* & No. (\%) & p-value \\
\hline Age (yr) & & 0.004 & & 0.024 \\
\hline 20-39 & $14 / 108(13.0)$ & & $8 / 324(2.5)$ & \\
\hline $40-59$ & $36 / 230(15.7)$ & & $30 / 690(4.3)$ & \\
\hline$\geq 60$ & $10 / 25(40.0)$ & & $7 / 75(9.3)$ & \\
\hline Gender & & 0.708 & & 0.039 \\
\hline Male & $49 / 302(16.2)$ & & $32 / 906(3.5)$ & \\
\hline Female & $11 / 61(18.0)$ & & $13 / 183(7.1)$ & \\
\hline Number of family & & 0.918 & & 0.072 \\
\hline 1 & $11 / 66(16.7)$ & & $3 / 48(29.2)$ & \\
\hline $2-3$ & $27 / 160(16.9)$ & & $25 / 449(21.8)$ & \\
\hline$\geq 4$ & $20 / 132(15.2)$ & & $17 / 592(16.2)$ & \\
\hline \multirow[t]{2}{*}{ Marital status (pre- vs. post-injury) } & & Pre 0.385 & & 0.007 \\
\hline & & Post 0.064 & & \\
\hline \multirow[t]{2}{*}{ Married } & Pre 29/173 (16.8) & & $28 / 833(3.4)$ & \\
\hline & Post 36/198 (18.2) & & & \\
\hline \multirow[t]{2}{*}{ Unmarried } & Pre 26/172 (15.1) & & $8 / 182(4.4)$ & \\
\hline & Post 12/115 (10.4) & & & \\
\hline \multirow[t]{2}{*}{ Divorced, widowed, separated } & Pre 5/18(27.8) & & $8 / 73(11.0)$ & \\
\hline & Post $12 / 50(24.0)$ & & & \\
\hline Income & & 0.130 & & $<0.001$ \\
\hline 1st quartile & $4 / 13(30.8)$ & & $17 / 130(13.1)$ & \\
\hline 2nd quartile & $19 / 102(18.6)$ & & $13 / 228(5.7)$ & \\
\hline 3rd quartile & $8 / 50(16.0)$ & & $8 / 334(2.4)$ & \\
\hline 4th quartile & $13 / 125(10.4)$ & & $3 / 367(0.8)$ & \\
\hline Education & & 0.321 & & $<0.001$ \\
\hline$<$ Elementary school & $6 / 25(24.0)$ & & $18 / 159(11.3)$ & \\
\hline$<$ High school & $39 / 222(17.6)$ & & $10 / 152(6.6)$ & \\
\hline College \& Over & $15 / 116(12.9)$ & & $17 / 778(2.2)$ & \\
\hline Occupation & & 0.179 & & $<0.001$ \\
\hline White collar & $8 / 76(10.5)$ & & $5 / 290(1.7)$ & \\
\hline Blue collar & $5 / 19(26.3)$ & & $17 / 540(3.1)$ & \\
\hline No occupation & $46 / 266(17.3)$ & & $23 / 259(8.9)$ & \\
\hline Self-Perceived health & & 0.059 & & $<0.001$ \\
\hline Very good & $3 / 16(18.8)$ & & $0 / 70(0.0)$ & \\
\hline Good & $5 / 78(6.4)$ & & $12 / 434(2.8)$ & \\
\hline Moderate & $29 / 169(17.2)$ & & $10 / 411(2.4)$ & \\
\hline Poor & $19 / 85(22.4)$ & & $17 / 151(11.3)$ & \\
\hline Very poor & $4 / 15(26.7)$ & & $6 / 23(26.1)$ & \\
\hline Outpatient clinic visit within the last 2 weeks & & 0.888 & & 0.016 \\
\hline Yes & $29 / 170(17.1)$ & & $19 / 285(6.7)$ & \\
\hline No & $31 / 193(16.1)$ & & $26 / 804(3.2)$ & \\
\hline Hospital admission within the last 12 months & & 0.872 & & 0.579 \\
\hline Yes & $18 / 113(15.9)$ & & $2 / 92(2.2)$ & \\
\hline No & $42 / 246(17.1)$ & & $43 / 997(4.3)$ & \\
\hline
\end{tabular}


Table 3. Continued

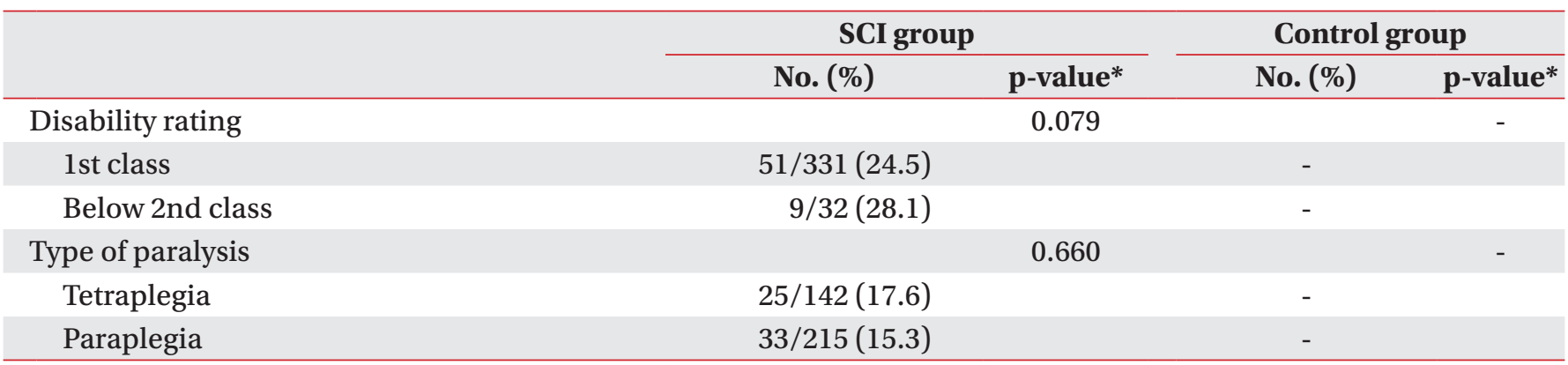

SCI, spinal cord injury.

*Pearson chi-square test.

Table 4. Multiple logistic regression model for inaccessibility to medical services

\begin{tabular}{lccc}
\hline & Odds ratio & $\mathbf{9 5 \%}$ CI & p-value \\
\hline $\begin{array}{l}\text { SCI } \\
\begin{array}{l}\text { No (general popula- } \\
\text { tion) }\end{array}\end{array}$ & 1.00 & - & - \\
Yes (SCI persons) & 4.08 & $2.07-8.03$ & $<0.001$ \\
$\begin{array}{l}\text { Age (yr) } \\
\geq 60\end{array}$ & 1.00 & - & - \\
\hline $40-59$ & 0.87 & $0.32-2.36$ & 0.784 \\
$20-39$ & 0.94 & $0.43-2.07$ & 0.888 \\
\hline
\end{tabular}

Income

$\begin{array}{lrcr}\text { 4th quartile } & 1.00 & - & - \\ \text { 3rd quartile } & 1.64 & 0.77-3.47 & 0.198 \\ \text { 2nd quartile } & 2.65 & 1.35-5.17 & 0.004 \\ \text { 1st quartile } & 6.21 & 2.69-14.32<0.001 \\ \text { Number of family } & & & \\ \geq 4 & 1.00 & - & - \\ 2-3 & 0.63 & 0.22-1.81 & 0.389 \\ 1 & 0.98 & 0.58-1.67 & 0.946\end{array}$

Education

\begin{tabular}{|c|c|c|c|}
\hline College \& over & 1.00 & - & - \\
\hline$<$ High school & 1.71 & $0.91-3.23$ & 0.096 \\
\hline$<$ Elementary school & 2.18 & $1.03-4.63$ & 0.043 \\
\hline \multicolumn{4}{|l|}{ Occupation } \\
\hline White collar & 1.00 & - & - \\
\hline Blue collar & 1.13 & $0.52-2.45$ & 0.765 \\
\hline No occupation & 1.76 & $0.88-3.52$ & 0.111 \\
\hline \multicolumn{4}{|l|}{ Marital status } \\
\hline Married & 1.00 & - & - \\
\hline Unmarried & 0.73 & $0.34-1.57$ & 0.419 \\
\hline $\begin{array}{l}\text { Divorced, widowed, } \\
\text { separated }\end{array}$ & 0.95 & $0.44-2.05$ & 0.895 \\
\hline
\end{tabular}

SCI, spinal cord injury; CI, confidence interval.
Factors associated with access to medical services

Table 3 shows the results of the chi-square tests for inaccessibility to medical services and each socioeconomic or psychological variable between the SCI group and the CG. Age was the only significantly related factor for access to medical services in the SCI group $(\mathrm{p}<0.05)$, whereas age $(\mathrm{p}<0.05)$, gender $(\mathrm{p}<0.05)$, marital status $(\mathrm{p}<0.05)$, income $(\mathrm{p}<0.001)$, education $(\mathrm{p}<0.001)$, occupation $(p<0.001)$, self-perceived health $(p<0.001)$, and visiting an outpatient clinic within the last 2 weeks $(\mathrm{p}<0.05)$ were significantly related in the CG.

The multiple logistic regression analysis showed that SCI was an independent influencing factor for inaccessibility to medical services (odds ratio, 4.08) (Table 4).

\section{DISCUSSION}

The present study revealed that $16.5 \%$ people with SCI experienced inaccessibility to medical services, which was much higher than that in the CG (4.1\%). The reasons for inaccessibility were due to transportation and economic burden, which could be considered environmental barriers rather than personal factors. In contrast, the reasons for inaccessibility to medical services in the CG were availability (medical services were not available when required) and acceptability (mild symptoms). These factors could be considered personal rather than environmental.

Hwang et al. [5] reported that Korean people with disabilities experience barriers to medical services more than that of the GP. They showed lack of money as the main reason for inaccessibility, followed by inaccessible transportation. In general, people with disabilities have barriers accessing medical services because they 
require treatment due to chronic diseases and secondary complications while their income is low [2,3]. However, we found that inaccessible transportation was the most important reason for inaccessibility to medical services in persons with SCI. This result agrees with that of previous studies showing transportation as the main barrier to people with severe physical disabilities [13-18]. In people with SCI, physical conditions related to accessibility to medical services could be different from other types of disabilities because people with SCI have complicated characteristics including motor disturbances, excretion impairment, and pressure sores [13], suggesting that social policies to eliminate or reduce barriers to medical services for the persons with SCI are necessary.

In a univariate analysis for the SCI group, age was the only factor that was related with inaccessibility to medical services, whereas many socioeconomic factors, including marital status, income and educational level were related with inaccessibility in the CG. In other words, socioeconomically vulnerable people in the CG, such as females, older people, people who do not have a spouse due to divorce, bereavement or separation, unemployment, people with low income or low education level showed high inaccessibility to medical services than those who were not. In contrast, the SCI group proved to have inaccessibility to medical services regardless of demographic and socio-economic status except age. This is different from preceding research revealing that age, gender, income, and subjective health conditions influence accessibility to medical services in people with disabilities $[5,10,11]$. It seems that other factors except matched age were not different because demographic and socio-economic status was lower in the SCI group. If the SCI group contained people with higher socio-economic status or larger families, there would have been more similar factors of inaccessibility as in the CG.

Dryden et al. [14] reported that people with SCI need more medical services than those of a CG. Beatty et al. [19] demonstrated the disabled subjects including those with SCI who have poor health and lower income are the least likely to receive health services. In addition, Cox et al. [20] documented that people with SCI need medical services but experience difficulties accessing them. Our results correspond well with those of these previous studies. Table 4 shows that having SCI in itself is a very important factor causing inaccessibility to medical services. People with SCI experienced inaccessibility to medical services four times higher than the CG despite controlling for age, sex, income, and other factors. McColl et al. [10] reported people with disabilities experience inaccessibility 2.16 times more than the GP. In addition, Smith [11] showed that women with disabilities have problems of access to medical services 2.26 times more than women without disabilities. In particular, women with functional losses of activities of daily living, instrumental activities of daily living, and mobility experience this healthcare service barrier 3.78 times more often. We infer from these results that people with SCI who have problems with physical accessibility have further barriers to use medical services compared to people with other types of disabilities.

It is still challenging for those with SCI to use the public transportation system, such as a bus, subway, or train. Although there are taxi services designated for the disabled in Korea, passengers must make reservations several weeks in advance before visiting a hospital [15]. Although people with a disability can use individual transportation as a last resort, there are more barriers to medical services including parking places and stairs [16]. These barriers might contribute to inaccessibility in the SCI group regardless of socio-economic status including income and education level.

We identified inaccessible transportation as a major barrier to medical services. A transportation system specifically designed for people with mobility impairments as well as deductions for medical expenses should be addressed to enhance medical accessibility for subjects with SCI.

Our study have limitations. First, only medical services provided by a doctor were considered when evaluating accessibility to medical services. We did not include a broad range of medical services, such as health promotion programs, health screening examinations, or services delivered by other healthcare providers. Second, the SCI group could be considered an active group among the entire SCI population because they were members of the KSCIA. This may have caused an underestimate of accessibility barriers in people with SCI.

In conclusion, people with SCI experienced barriers to access of medical services when medically required more frequently than the CG. Reasons for inaccessibility to medical services were environmental rather than personal factors compared to those in the CG. A transportation 
system specifically designed for people with motor function impairments along with a medical cost exemption is necessary to improve accessibility to medical services by persons with SCI.

\section{CONFLICT OF INTEREST}

No potential conflict of interest relevant to this article was reported.

\section{REFERENCES}

1. Varma AK, Das A, Wallace G 4th, Barry J, Vertegel AA, Ray SK, et al. Spinal cord injury: a review of current therapy, future treatments, and basic science frontiers. Neurochem Res 2013;38:895-905.

2. Shin JC, Kim DH, Yu SJ, Yang HE, Yoon SY. Epidemiologic change of patients with spinal cord injury. Ann Rehabil Med 2013;37:50-6.

3. Krause JS, Terza JV, Erten M, Focht KL, Dismuke CE. Prediction of postinjury employment and percentage of time worked after spinal cord injury. Arch Phys Med Rehabil 2012;93:373-5.

4. Chen J, Hou F. Unmet needs for health care. Health Rep 2002;13:23-34.

5. Hwang B, Chun SM, Park JH, Shin HI. Unmet healthcare needs in people with disabilities: comparison with the general population in Korea. Ann Rehabil Med 2011;35:627-35.

6. Eun SJ, Hong JY, Lee JY, Lee JS, Kim Y, Kim YI, et al. Differences in medical care utilization rates of the disabled and the non-disabled with ambulatory care sensitive conditions. J Prev Med Public Health 2006;39:411-8.

7. Henry AD, Long-Bellil L, Zhang J, Himmelstein J. Unmet need for disability-related health care services and employment status among adults with disabilities in the Massachusetts Medicaid program. Disabil Health J 2011;4:209-18.

8. Jacobi CE, Rupp I, Boshuizen HC, Triemstra M, Dinant HJ, van den Bos GA. Unmet demands for health care among patients with rheumatoid arthritis: indications for underuse? Arthritis Rheum 2004;51:440-6.

9. Kirschner KL, Breslin ML, Iezzoni LI. Structural impairments that limit access to health care for patients with disabilities. JAMA 2007;297:1121-5.
10. McColl MA, Jarzynowska A, Shortt SE. Unmet health care needs of people with disabilities: population level evidence. Disabil Soc 2010;25:205-18.

11. Smith DL. Disparities in health care access for women with disabilities in the United States from the 2006 National Health Interview Survey. Disabil Health J 2008;1:79-88.

12. Lin JD, Loh CH, Yen CF, Li CW, Chwo MJ, Wu JL. Medical care services for people with intellectual disabilities living in the general community: a cross-sectional survey of inpatient care utilization in Taiwan, 2001. Disabil Rehabil 2007;29:1411-6.

13. Donnelly C, McColl MA, Charlifue S, Glass C, O'Brien P, Savic G, et al. Utilization, access and satisfaction with primary care among people with spinal cord injuries: a comparison of three countries. Spinal Cord 2007;45:25-36.

14. Dryden DM, Saunders LD, Rowe BH, May LA, Yiannakoulias N, Svenson LW, et al. Utilization of health services following spinal cord injury: a 6-year followup study. Spinal Cord 2004;42:513-25.

15. Cui X, Chung SW. Basic research for the design of taxis for the handicapped. Arch Des Res 2009;5:212-3.

16. Lee JY, Jang MW, Kim KY, Yun SM, Lee JH, Jeong J, et al. Accessibility of the disabled to health care institution: a case study of Chongno-gu in Seoul. Korean J Health Policy Adm 2006;16:19-36.

17. Vissers $M$, van den Berg-Emons R, Sluis T, Bergen M, Stam H, Bussmann H. Barriers to and facilitators of everyday physical activity in persons with a spinal cord injury after discharge from the rehabilitation centre. J Rehabil Med 2008;40:461-7.

18. Park JH, Lee JS, Lee JY, Gwack J, Park JH, Kim YI, et al. Disparities between persons with and without disabilities in their participation rates in mass screening. Eur J Public Health 2009;19:85-90.

19. Beatty PW, Hagglund KJ, Neri MT, Dhont KR, Clark MJ, Hilton SA. Access to health care services among people with chronic or disabling conditions: patterns and predictors. Arch Phys Med Rehabil 2003;84:141725.

20. Cox RJ, Amsters DI, Pershouse KJ. The need for a multidisciplinary outreach service for people with spinal cord injury living in the community. Clin Rehabil 2001;15:600-6. 